\title{
Elementary, Sebaceous, Solo- Steatocystoma Simplex
}

\author{
Anubha Bajaj* \\ Consultant Histopathologist, Panjab University, India \\ Received: May 01, 2019; Published: May 14, 2019 \\ *Corresponding author: Anubha Bajaj, Consultant Histopathologist, Panjab University, India
}

\section{Preface}

Steatocystoma simplex was initially scripted as a definitive entity and an extremely exceptional, benign adnexal tumour by Brownstein in 1982. Steatocystoma simplex is a solitary analogue of steatocystoma multiplex. The disorder is devoid of genetic transmission. Steatocystoma simplex as a clinical condition is distinct from steatocystoma multiplex. Solitary lesions delineated in steatocystoma simplex generally simulate clinical and histological aspects of multiple lesions of steatocystoma multiplex. Cutaneous tumour of steatocystoma simplex appears as a circumscribed, nevoid malformation of the pilosebaceous duct junction [1,2]. Steatocystoma simplex also carries the nomenclature of sebaceous duct cyst. Steatocystoma multiplex with representative multitudinous cysts are a frequently elucidated disorder, in contrast to the solitary cysts enunciated in steatocystoma simplex, which arise in adulthood.

\section{Disease Characteristics}

Steatocystoma simplex can be segregated from steatocytsoma multiplex on account of attributes such as a solitary lesion which appears sporadically in adulthood, progresses gradually and displays a non-heritable pattern of disease emergence. Exceptionally, the condition can be associated with Gardner's syndrome, pachyonychia congenita or ectodermal dysplasia. Disease onset is frequent at puberty and full blown clinical features are elucidated in second to fourth decade of life. There is a slight female predominance. A family history of disease emergence or recurrence of lesion is absent [2,3]. Steatocystoma simplex is a benign condition which demonstrates the insurgence of dermal tumours frequently cogitated in diverse locations such as the forehead, face, nose, neck, axilla, chest, eyelids and upper limbs. Steatocystoma simplex occurs preponderantly on the face, however, lesions on the scalp are extremely rare. Additional infrequent sites of the tumefaction include the dorsum, lower limbs, oral cavity, periocular region and perineum. Lesions of steatocystoma simplex can be localized in the lacrimal caruncle constituted of conjunctiva and skin [3,4]. Steatocystoma simplex can exceptionally appear in the female external genital region. Glandular architecture is generally oedematous.

\section{Clinical Elucidation}

Characteristic lesions comprise of asymptomatic nodules or papules which are firm, flesh coloured to yellow with a magnitude ranging from one centimetre to three centimetres, although miniature lesions of 2 millimetre dimension can be elucidated. Nodules of steatocystoma simplex are usually firm and non-tender. Identical or multiple lesions are frequently absent. Papules can originate on specific sites such as scalp, eyelids or adjunct locales and gradually evolve. Predominantly asymptomatic lesions of steatocystoma simplex are devoid of an inflammatory component and display a normal skin tone. Cystic lesions are soft, mobile, preponderantly intra-cutaneous and demonstrate a definitive circumscription. Cysts can clinically resemble trichilemmal cysts. Adjunctive or identical cysts at divergent locations generally do not ensue $[4,5]$. Alternatively , skin coloured, deep seated, soft to cystic, miniscule tumefaction can be demonstrated.

\section{Histological Elucidation}

Gross examination demonstrates a tumefaction which is yellowish with a smooth extraneous surface or a cyst impacted with yellowish fluid. The tumefaction is preferably removed intact without fissuring during histological processing. Steatocystoma simplex depicts miniature cysts coated with an epithelial lining which recapitulates the corrugated cuticle of sebaceous ducts of the accompanying sebaceous glands. Morphology depicts a cystic cavity which is vacant, exhibits a serpiginous perimeter and is layered with attenuated, stratified squamous epithelium. External surface displays a corrugated cuticle with an absent to minimal stratum granulosum. The cystic mass circumscribed with a stratified squamous epithelium demonstrates a saw tooth configuration. Innermost region of the cyst exhibits a conspicuous, acellular, homogenous, eosinophilic and compressed horny layer [5,6]. Attenuated cyst walls lined with stratified squamous epithelium lack a definitive stratum granulosum and demonstrate an abundance of sebaceous glands. Sebaceous glands and flattened sebaceous gland lobules commonly abut or appear contiguous to the cyst wall. The hollow, 


\section{Open Access Journal of Surgery}

cystic nodule, layered with an undulating squamous epithelium is configured within the dermis. An eosinophilic, hyalinised cuticle is cogitated within the cystic lumen in the absence of sebaceous glands. . Epithelial configurations recapitulating hair follicles project from the cyst wall into the enveloping stroma. Epithelial cell layer can be partially undulating. Cyst lumen is devoid of hair and associated dermo-epidermal or mesenchymal components. Abortive tracts of lining squamous epithelium can project from the cyst to superficial epidermal surface. Disorders such as a hybrid epidermo-apocrine cyst and apocrine or eccrine hidrocystoma can coexist [6,7] (Figures 1-10).

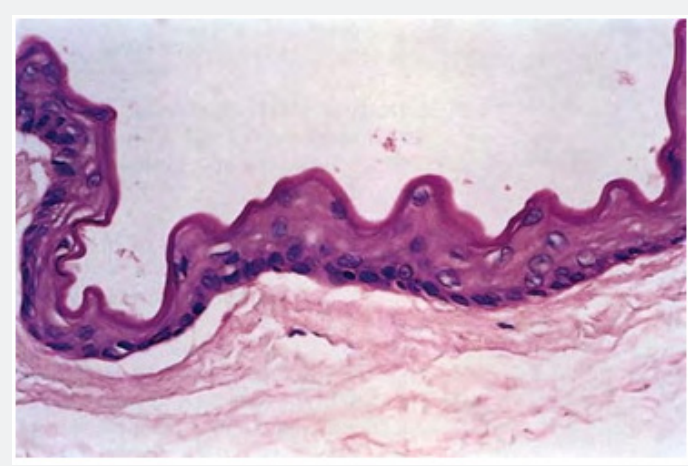

Figure 1: Corrugated, stratified squamous epithelium in steatocystoma simplex.

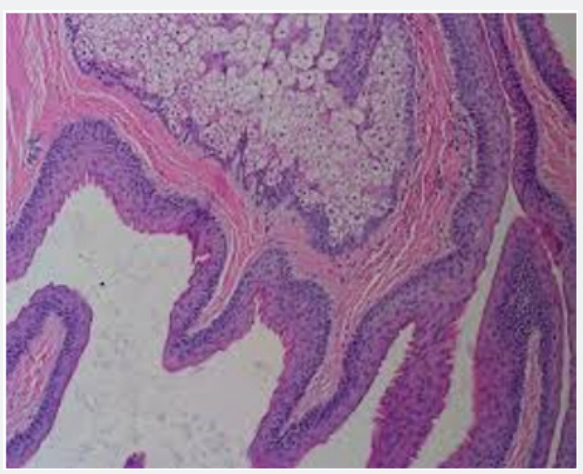

Figure 2: Abutted sebaceous glands, compressed, eosinophilic horny layer and epithelial lining in steatocystoma simplex.

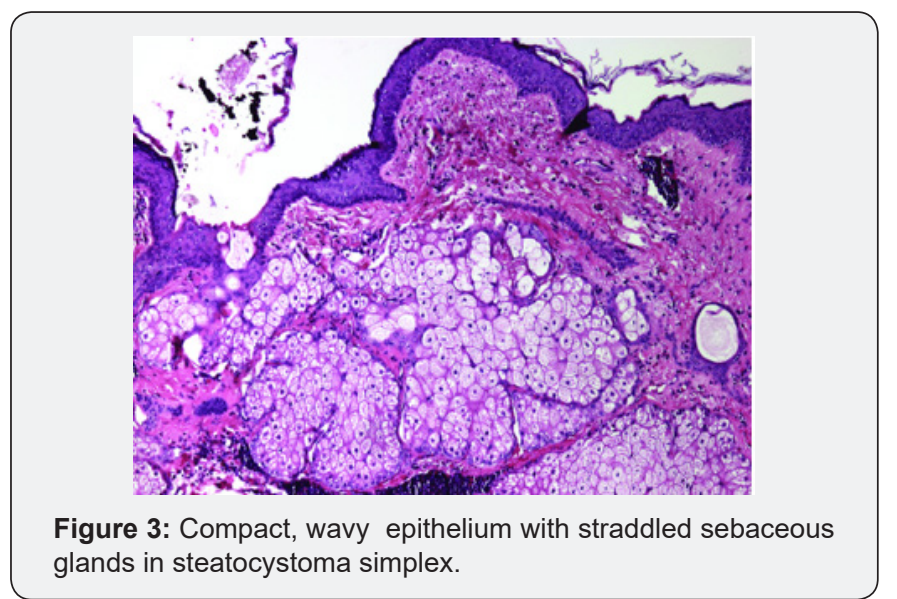

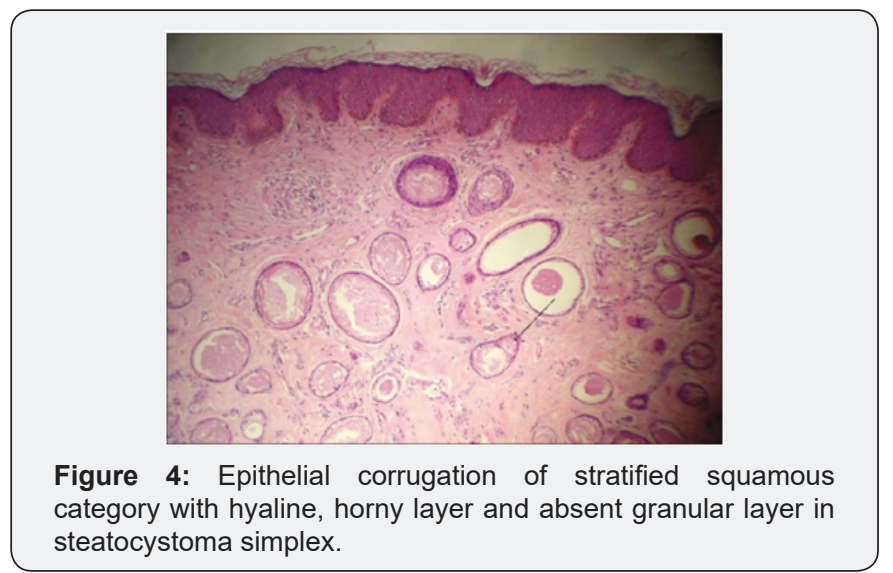

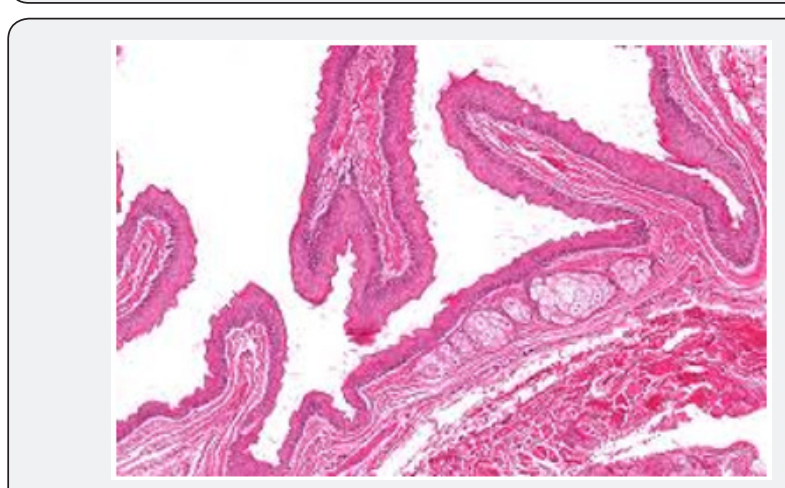

Figure 5: Steatocystoma simplex depicting epithelial festoons and adjacent sebaceous glands.
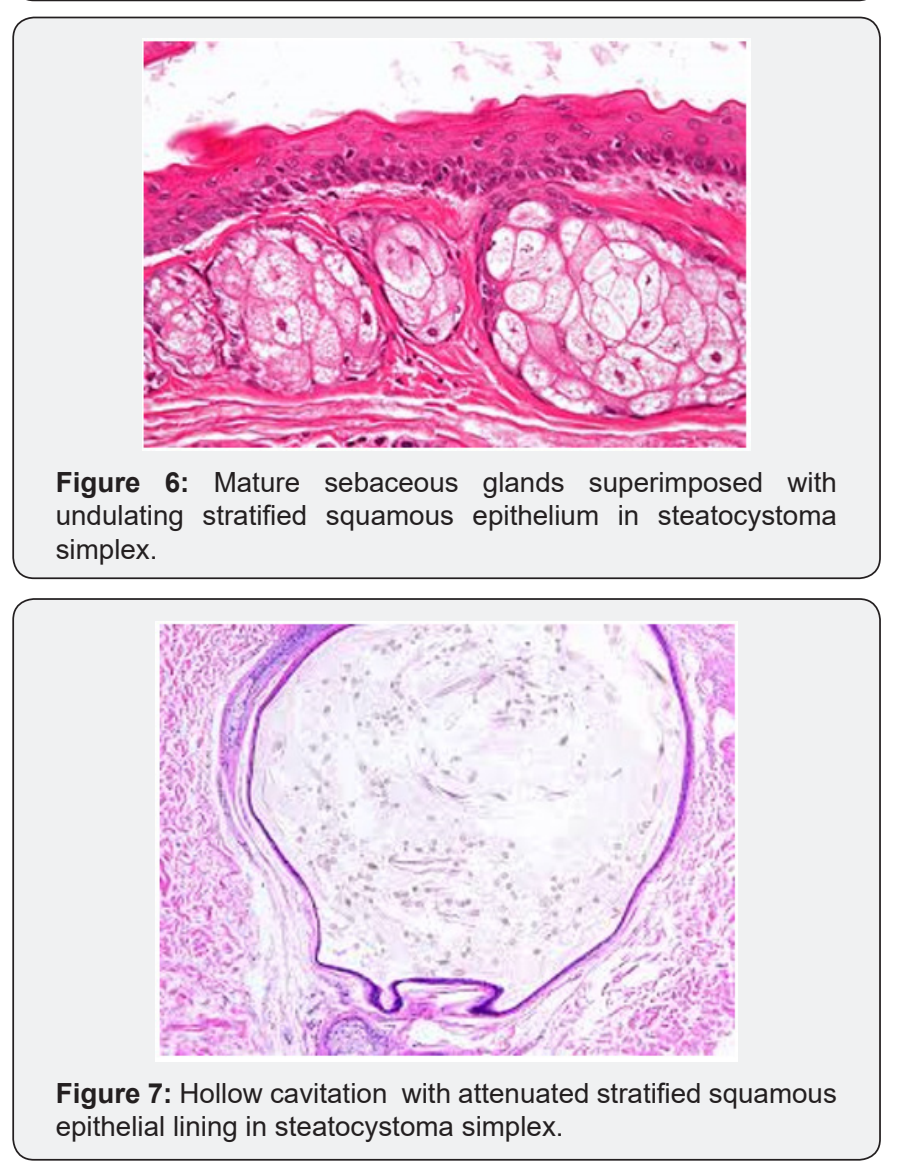


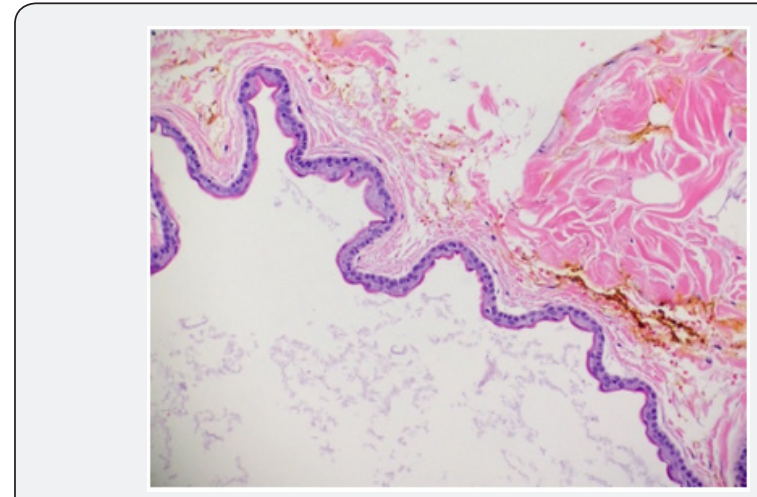

Figure 8: Corrugated cystic cavity with shrivelled stratified squamous epithelium in steatocystoma simplex.

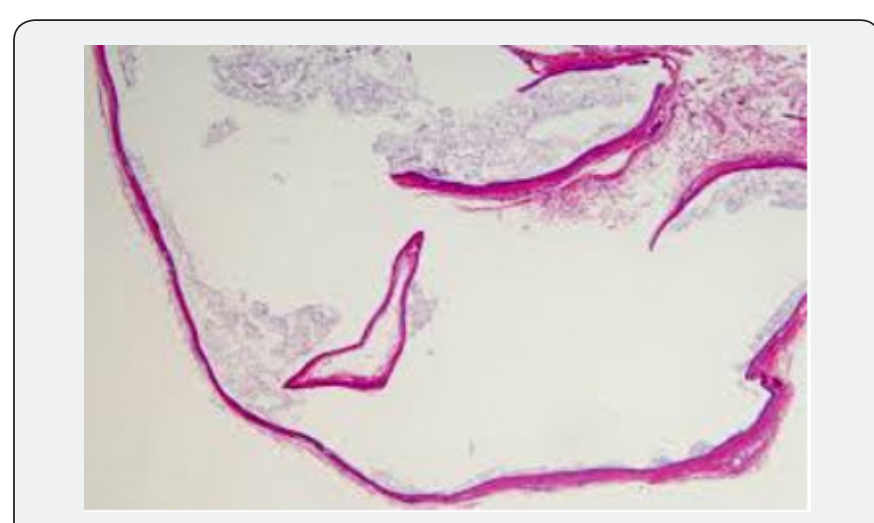

Figure 9: Stretched out cystic cavity and fragile, lining stratified squamous epithelium in steatocystoma simplex.

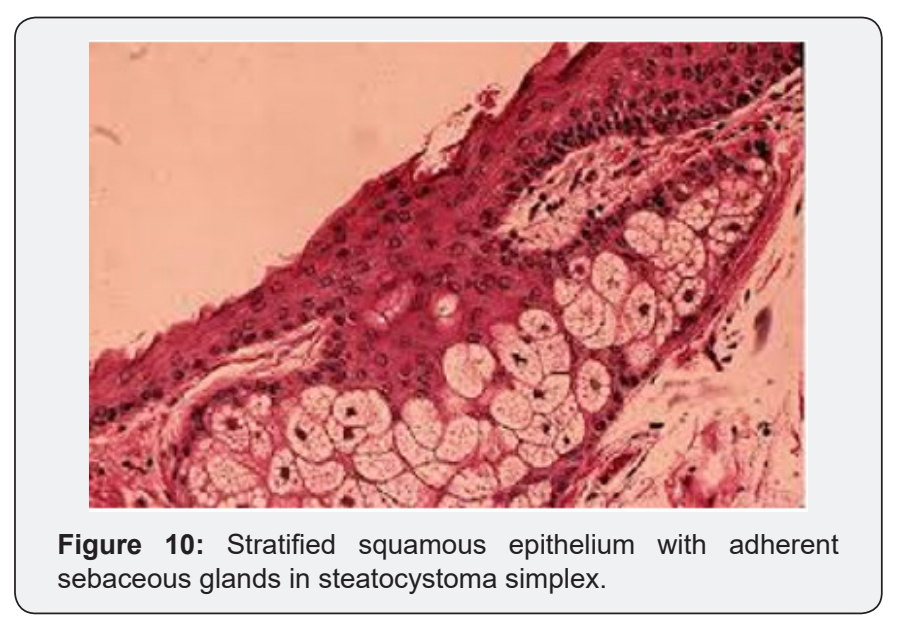

\section{Differential Diagnosis}

Steatocystoma simplex necessitates a demarcation from the cited lesions:

i. An oncocytoma which is a gradually evolving, cystic nodule of reddish- blue or tan spectrum.

ii. Cystic sebaceous gland hyperplasia, sebaceous gland adenoma and lipogranuloma, conditions which demonstrate yellow nodules, however the aforesaid lesions depict diverse, although typical clinical and morphological attributes. iii. Dermoid cysts recapitulate clinical and histological aspects of a steatocystoma. Nevertheless, dermoid cyst is devoid of a wavy, epithelial layer and can demonstrate hair within the cystic lumen $[7,8]$.

iv. Cutaneous keratocyst can simulate a steatocytsoma on histology with a festooned epithelial lining in conjunction with a thickened cyst wall, a layer of stratified squamous epithelium essentially devoid of a granular cell layer, sebaceous glands and lobular configuration.

v. Steatocytoma simplex requires a distinction from lesions of steatocystoma multiplex. Steatocystoma multiplex characteristically depicts multitudinous lesions disseminated over the torso. The disorder classically demonstrates an autosomal dominant mode of inheritance.

vi. Hidrocystoma, pigmented follicular cysts or vellus horn cysts are disorders for which distinction from a steatocystoma simplex is a pre-requisite. Hidrocystoma demonstrates typical, diagnostic histological characteristics $[8,9]$.

\section{Therapeutic Options}

Comprehensive surgical excision is the optimal mode of alleviating the tumefaction. Preferred therapy is simple surgical eradication of the cyst with an undamaged cyst wall in order to minimize the risk of reoccurrence. Tumefaction localized on lacrimal caruncle or adjunctive sites are surgically exterminated with the administration of local anaesthesia $[9,10]$. Alternative modes of therapy include cyst aspiration, cryosurgery, electrocautery and carbon dioxide laser therapy. Isotretinoin or cryotherapy can be additionally employed. Extensive monitoring usually demonstrates an absence of tumour recurrence subsequent to surgical elimination or progression of the steatocystoma [10].

\section{References}

1. Evans WH (1940) Tumours of the lacrimal caruncle: a study of 200 collected cases. Arch Opthalmol 24: 83-106.

2. Brownstein MH (1982) Steatocystoma simplex: a solitary steatocystoma. Arch Dermatol 118: 409-411.

3. Ishida Y, Takahashi Y, Takahashi E, Kitaguchi Y, Kakizaki H (2016) Steatocystoma simplex of the lacrimal caruncle: a case report. BMC online 16(1): 183.

4. Xiangdong Xu Jingwen Zhu (2018) 109 Steatocystoma simplex in labia majora. Am J Clin Pathol 149: S42-S53.

5. Hyun DN, Won JH (2008) A case of steatocystoma simplex involving the scalp. Ann Dermatol 20(4): 230.

6. Kazakov DV, Michal M (2012) Steatocystoma. In: Cutaneous Adnexal Tumours. Wolters, Kluwer Health / Lippincott Williams and Wilkins: Philadelphia, United States, pp. 368-372.

7. Kirkham N (2009) Tumours and cysts of the Epidermis. Lever's Histopathology of the Skin pp. 791-849.

8. Procianoy F, Golbert MB, Golbspan L, Duro KM, Bocaccio FJ (2009) Steatocystoma simplex of the eyelid. Opthal Plast Reconstr Surg 25: 147-148. 
9. Tirakunwichacha S, Vaivanijkul J (2009) Steatocystoma simplex of the eyelid. Opthal Plast Reconstr Surg 25: 49-50.
10. Levy J, Ilsar M Deckel Y, Maly A, Pe'er J (2009) Lesions of the caruncle a description of 42 cases and a review of literature. Eye 23: 1004-1018.

Your next submission with Juniper Publishers
will reach you the below assets
- Quality Editorial service
- Swift Peer Review
- Reprints availability
- E-prints Service
- Manuscript Podcast for convenient understanding
- Global attainment for your research
- Manuscript accessibility in different formats
( Pdf, E-pub, Full Text, Audio)
- Unceasing customer service
Track the below URL for one-step submission
https://juniperpublishers.com/online-submission.php

